\title{
LA DIFÍCIL RELACIÓN ENTRE UNA DECLARATORIA DE INCONSTITUCIONALIDAD ERGA OMNES Y SUS EFECTOS PRÁCTICOS EN MÉXICO
}

\author{
THE DIFFICULT RELATIONSHIP BETWEEN ERGA OMNES \\ DECISIONS IN CONSTITUTIONAL JUDICIAL REVIEW \\ AND THEIR PRACTICAL CONSEQUENCES IN MEXICO
}

\author{
David GARCÍA SARUBBI
}

RESUMEN: Este es un artículo que propone adelantar un paso en la discusión sobre el control constitucional. Más allá de la interrogante clásica sobre la conveniencia de un aparato judicial revisor de los méritos y formas de los actos de los órganos políticos con legitimidad democrática, el contexto actual nos obliga a explorar nuevos tópicos que surgen una vez que se presupone dicho control. Uno de ellos tiene que ver con sus efectos en el contexto en el que pueden ser más críticos: cuando decretan la inconstitucionalidad de normas con efectos erga omnes. Estos efectos sólo pueden observarse en nuestro país en las controversias y acciones de inconstitucionalidad, juicios previstos por el artículo 105 constitucional, en los cuales las sentencias no pueden tener efectos retroactivos salvo en materia penal. El objetivo es demostrar que la determinación de prohibir o permitir la retroactividad de estas sentencias depende de otros temas de teoría constitucional como la naturaleza de los tribunales constitucionales, de la función jurisdiccional y el papel de los principios constitucionales.

Palabras clave: derecho constitucional; efectos de sentencias en controversias y acciones de inconstitucionalidad; retroactividad y prospectividad; jurisdicción constitucional.
ABSTRACT: This is a paper that aims to deepen in the national debate referring to the constitutional judicial review. If we take for granted the convenience of having a judicial power to review the merits of the enactments of the political branches, though the debate has not been settled, we face some new points that need to be discussed. Among those in our country, it is the effects of the decisions of the sort referred to when they might be the most far-reaching: when they are issued erga omnes. In Mexico this is the case when acting within "controversias" and "acciones de inconstitucionalidad" which according to Article 105 are to be solved with general effects with no retroactive effects save in criminal law. The main goal of this paper is the proving that the discussion of the convenience of retroactive effects in these processes is an essential one and that it depends directly upon the discussion of important issues of constitutional law such as the nature of the judicial power, of the judicial function and the roll of constitutional principles.

Descriptors: Constitutional Law; Resolution's Effects; Constitutional Review, Retroactivity and Prospectivity; Constitutional Jurisdiction. 


\section{INTRODUCCIÓN}

Asumir el valor normativo de la Constitución es concebir un sistema de normas escalonado más acabado que el del Estado de derecho decimonónico, dado que el último peldaño del orden jurídico, ahora ubicado en la Constitución, termina por cerrar lógicamente a todo el sistema: toda la comunidad jurídica, incluido el legislador democrático, está sometido al derecho.

Luigi Ferrajoli afirma que un costo indispensable de vivir en un Estado constitucional, como el descrito, es operar en un orden jurídico con un fenómeno virtuoso y patológico a la vez: la existencia de lagunas y antinomias normativas. La Constitución, por los contenidos de difícil satisfacción material que contiene, siempre es un programa inacabado que, constantemente, contrasta con las producciones jurídicas de los poderes públicos (antinomias) y con sus omisiones (lagunas). Se trata de un fenómeno patológico, como es claro, porque evidencia el incumplimiento del sistema de los presupuestos básicos en que descansa su legitimidad, pero, a su vez, es virtuoso porque dota a la sociedad de un parámetro objetivo de control sobre el poder público y una vía de legitimación para los actores políticos frente a ésta. ${ }^{1}$

Desde Kelsen hasta nuestros días este fenómeno se ha considerado aceptable y funcional por la existencia de un mecanismo, hasta ahora considerado eficaz, que contiene sus efectos nocivos dentro de márgenes aceptables: la jurisdicción constitucional. La aplicación de la jurisdicción en este último peldaño normativo permite imponer los contenidos constitucionales sobre la dinámica política, siempre presta a desbordar los límites que la rodean.

En nuestro país estos rasgos han adquirido una notoriedad especialmente intensa en los últimos tiempos. La sociedad cada vez es más sensible para señalar la disociación del plano constitucional del legal (el tema del aborto es un ejemplo de un debate llevado a cabo en la sociedad en el que se utiliza el techo constitucional para evaluar una determinada producción legislativa), por lo que las mencionadas lagunas y antinomias ya no producen la indeferencia social conveniente para el poder público de antes. Por otra parte, la Suprema Corte de Justicia de la Nación, con

1 Véase Ferrajoli, Luigi, Derechos y garantias. La ley del más débil, Madrid, Trotta, 2006. 
las funciones que lo invisten como un tribunal constitucional, muestra un impulso cada vez más decido en ejercer el control constitucional en nuestro país (el juicio sobre la "ley televisa" ha sido señalado como un ejemplo de esta determinación asumida).

Por tanto, podemos decir que en México la puesta en marcha del principio de supremacía constitucional tiene la viveza que suelen mostrar la normalidad de las democracias modernas porque, por un lado, el plano constitucional es utilizado estructuralmente como un referente de descrédito de los abusos del poder público y, por el otro, no existe timidez en activar ni en ejercer el mecanismo diseñado por el sistema para controlar la disociación cotidiana entre la carta magna y el resto del orden jurídico.

Si aceptamos, por tanto, que hemos superado en buena parte el debate fundacional de cómo instaurar un sistema de control constitucional en nuestro país - aunque, ciertamente, no sea un tema totalmente acabado-, me parece que podemos concentrarnos en un problema de no menor entidad, referido a los alcances de dicho control para hacer valer su eventual conclusión de que parte del ser jurídico no debe ser: los efectos de una declaratoria de inconstitucionalidad. En mi opinión, el reto teórico no sólo lo ofrecen las declaratorias realizadas históricamente vía amparo, que tienen el reducido efecto de inaplicar normas irregulares a los particulares en los casos concretos, sino que lo ofrece sobre todo aquellas que gozan de la mayor eficacia en todo el sistema, emitidas en las controversias constitucionales y en las acciones de inconstitucionalidad: ${ }^{2}$ la invalidez erga omnes de normas generales.

En estas dos instancias (las controversias constitucionales y las acciones de inconstitucionalidad), el problema de los efectos de una sentencia de la Suprema Corte que califica cierta ley de inconstitucional, como las que emiten los tribunales constitucionales en el resto del mundo, no sólo genera interés por su transfondo político: la relación entre jueces y representantes populares (relación entre derecho y política); ni tampoco por las peculiares y complejas condiciones de control jurídico de un texto como la Constitución, sino también, y sobre todo, por el manejo conceptual, que implica el peligro práctico de su efectividad: la "expulsión" definitiva de normas generales.

2 Los dos juicios de control constitucional diseñados para que los órganos del Estado mexicano puedan defenderse de los actos de otros órganos estatales, regulados en las dos primeras fracciones del artículo 105 de la Constitución Federal. 
No es igual de fácil concebir el aserto de que una norma secundaria cualquiera contradice algún contenido constitucional, qué se refiere al contraste de operadores deónticos, que aquel que dice que esta misma norma ha sido expulsada del orden jurídico por inconstitucional, qué se refiere a sus efectos prácticos, siempre problemáticos y que, por tanto, rebasa el plano estrictamente lógico y conceptual. Especialmente, la dimensión temporal de dichos efectos es un espacio en el que no existe un horizonte lo suficientemente claro respecto de los alcances de una declaratoria de este tipo. Cuando un tribunal concluye que una ley es inconstitucional ¿qué debe entenderse? ¿Que esa norma — cuya contradicción lógica con la norma suprema puede entenderse sin problemas - nunca ha existido en el tiempo?, esto es ¿que su aplicación efectiva sólo ha sido una cuestión fáctica que no está ligada a ningún basamento jurídico?, o bien ¿que ésta ha tenido una cierta validez temporal que termina con la sentencia estimatoria que recae sobre ella?; en otras palabras, ¿ha de entenderse que se trata de una medida que intenta corregir para el futuro algo reprochable constitucionalmente? o bien, ¿que estamos ante una corrección que intenta reivindicar todo el daño constitucional ocasionado a cualquier costo?

A mi parecer, esta cuestión de los efectos de una sentencia que decreta la inconstitucionalidad de normas generales no es una cuestión menor. Cierto, se trata de un problema técnico referido al impacto práctico de la jurisdicción constitucional en la realidad, sin embargo, el mismo no está desconectado en lo más mínimo del tema central: la máxima consecución de los fines contenidos en el código político del país. De la forma como se encaucen los efectos de las sentencia dictadas en estas instancias dependerán el mayor o menor grado de realización de la carta magna en un orden jurídico determinado.

En el presente artículo propongo una aproximación a este fenómeno de los efectos de una declaratoria de inconstitucionalidad desde tres planos distintos, cuyas líneas argumentativas justifican conclusiones diferentes: el institucional, el epistemológico y el axiológico. El propósito es hacer explícitos los supuestos en que se basan estas tres aproximaciones teóricas y reconstruir un modelo básico que incluya a éstos sobre el cual, finalmente, se pueda responder satisfactoriamente a la pregunta general: ¿qué efectos prácticos debe tener una declaratoria de inconstitucionalidad con valor erga omnes en el tiempo en nuestro sistema constitucional? 
En el plano institucional se intenta dilucidar qué es un tribunal constitucional; en el epistemológico se pregunta qué hace dicho tribunal realmente con el derecho, cuya aplicación debe tutelar, y en el axiológico se intenta dibujar un mapa de ponderación de los bienes y valores involucrados en esta cuestión (la reivindicación de las pautas constitucionales vulneradas y los principios formales en que se basa la estabilidad y eficacia del orden jurídico, como más adelante se verá).

El punto de partida y de referencia a lo largo de todo el presente trabajo lo ofrece el penúltimo párrafo de la fracción III del artículo 105 de la Constitución Política de los Estados Unidos Mexicanos, el cual traza el modelo que rige en nuestro sistema en este tema de la siguiente manera:

[1]a declaración de invalidez de las resoluciones a que se refieren las fracciones I y II de este artículo [controversias y acciones de inconstitucionalidad, respectivamente] no tendrá efectos retroactivos, salvo en la materia penal, en la que regirán los principios generales y disposiciones legales aplicables de esta materia.

Como se puede inferir con facilidad, el modelo escogido por el Constituyente permanente para nuestro país está diseñado para privilegiar un impacto pro futuro de las mismas. La Constitución limita su propia reivindicación en el tiempo. Prohíbe a la Suprema Corte de Justicia de la Nación incidir en el pasado, delimitando negativamente el ámbito de corrección de sus sentencias en estos dos juicios, salvo en la materia penal: el futuro.

Pongamos un ejemplo para mayor claridad. Si la Corte declara inconstitucional, en alguno de los dos juicios establecidos en la artículo 105 de la Constitución Federal, una ley que, por ejemplo, establece un trato discriminatorio en contra de un sector de la población al negarles el acceso a un bien público, sin que existiera razón que lo justifique, la declaratoria de inconstitucionalidad sólo podría tener, bajo el actual esquema normativo, efectos para el futuro, sin poder alterar las consecuencias jurídicas provocadas en el pasado, esto es, antes de la promoción del juicio, y, por tanto, el sector de la población afectado tendría que soportar el daño jurídico ya realizado y que de alguna forma subsiste. Supongamos que el bien público denegado se trata de una pensión o algún tipo de ayuda prestacional. Las consecuencias jurídicas negativas provocadas por la norma impugnada tendrían que respetarse $\mathrm{y}$, por tanto, estas personas no 
tendrían el derecho de que se les restituyeran los montos que no se les otorgó mientras que la norma era válida (si tuvieron que pagar servicios médicos privados u otro tipo de servicios o bienes, tendrían que cargar de forma definitiva con esos costos).

Supongamos, en otro caso, que la norma que se declara inconstitucional es una que establece un tipo de responsabilidad distinta a la penal (por ejemplo, civil, administrativa o política). Por ejemplo, una responsabilidad que se generara por "vagancia" o por cualquier otro tipo de conducta igualmente arbitraria y discriminatoria. Dado que la declaratoria de inconstitucionalidad no podría invalidar para el pasado la norma irregular, todas aquellas decisiones definitivas realizadas contra las personas tendrían que quedar intactas.

Dentro de la teoría procesal se ha denominado a este tipo de modelo ex nunc, palabra de origen latina que significa "desde ahora", con el propósito de distinguirlos de aquellos que no privilegian los efectos futuros de sus declaratorias de inconstitucionalidad, sino los pasados, los cuales se les conoce como ex tunc, locución que significa "desde siempre". Desde un modelo como el mexicano, una ley declarada inconstitucional sólo se invalida para el futuro y se mantiene válida para el pasado con excepción de la materia penal; en un modelo ex tunc, la misma puede ser inválida tanto para el fututo como para el pasado.

\section{EL PLANO INSTITUCIONAL}

El institucional es el primer plano analítico que abordaremos en este artículo porque aquí se pregunta por el autor de las sentencias, cuyos efectos ahora pretendemos estudiar. La respuesta que se formule a la pregunta ¿qué efectos debe tener una declaratoria de inconstitucionalidad? se hace depender aquí de la respuesta que se otorgue a una pregunta previa ¿qué es un tribunal constitucional? De la misma forma que se suele afirmar que las leyes sólo pueden provenir de un legislador, los reglamentos del ejecutivo y las sentencias de los jueces, la naturaleza de los tribunales constitucionales condicionan determinantemente la fisonomía de sus producciones normativas desde esta perspectiva y, especialmente, sus efectos en el tiempo.

Históricamente, esta interrogante admite dos respuestas provenientes de dos tradiciones trasatlánticas distintas. Se puede decir que un tribunal 
constitucional es una jurisdicción como cualquiera (americana) o bien un legislador negativo (europea).

Con el precedente Marbury vs. Madison emitido en 1803 se inauguró la judicial review en la tradición americana, y con éste un control de constitucionalidad que se recrea plenamente con el paradigma de la jurisdicción. Desde esta tradición, se considera que la Constitución es una norma jurídica como cualquiera, si bien la de mayor jerarquía dentro del sistema general, y por tanto, corresponde a cualquier juez aplicarla dentro de la función que tienen asignada de "decir el derecho". Dado que los jueces dicen el derecho, y dentro de éste se encuentra la Constitución, las sentencias que emiten se consideran declarativas, dado que se limitan a declarar algo prexistente (las normas jurídicas de la comunidad) y, por tanto, los efectos de dichas sentencias no tienen más límites que las impuestas por el objeto prexistente que se reafirma o se reconoce en los casos resueltos.

Si las declaratorias de inconstitucionalidad bajo este modelo son declarativas, es evidente que sus efectos pueden y, en algún sentido, deben retrotraerse hacia el pasado, por la razón de que la sentencia que la contiene declara la inexistencia de las normas impugnadas. Declaran, por ejemplo, que determinada ley nunca ha existido, por no ajustarse a la regla de reconocimiento del sistema (la Constitución) y, por tanto, no existen condiciones jurídicas pasadas realizadas al amparo de la ley impugnada que deban respetarse. Por tanto, el modelo ex tunc, en el que se privilegian los efectos retroactivos de las sentencias de los tribunales constitucionales, en un primer plano, puede venir acompañado de un entendimiento previo de la justicia constitucional como una auténtica jurisdicción emisora de resoluciones declarativas.

Por otra parte, el modelo ex nunc suele venir acompañado de un entendimiento del fenómeno de los tribunales constitucionales de corte europeo. Este modelo, cuya autoría se atribuye comúnmente a Hans Kelsen, desmonta de la justicia constitucional notas relevantes de la jurisdicción ordinaria. Según Kelsen, el control constitucional no debe corresponder a todos los jueces por igual, como el sistema americano, sino a un sólo órgano separado de los tres poderes del Estado (incluido el poder judicial) que de forma abstracta (ajena a los litigios concretos) analice la compatibilidad lógica entre las leyes y la Constitución. Para esta visión, se trata de una jurisdicción sui generis que no se puede confundir con la 
ejercida ordinariamente por el poder judicial. Un tribunal constitucional no puede equipararse a un juez común, sino a un órgano distinto a él, a un "legislador negativo", según Kelsen. ${ }^{3}$

Dado que un tribunal constitucional evalúa en abstracto la compatibilidad constitucional de normas generales, cuyo juicio afirmativo impone la consecuencia de la eliminación de dichas normas generales, se trata de un órgano encargado de expulsar normas generales, esto es, de derogar normas irregulares. Como sostiene García de Enterría, el modelo kelseniano o europeo del control de las leyes, gira alrededor de la idea de que este órgano no desempeña una función jurisdiccional común, sino de legislación negativa por la razón de que sus sentencias son, en realidad, actos de derogación de leyes. ${ }^{4}$

La construcción teórica de este modelo sobre estas premisas, lleva a afirmar a sus defensores que las declaratorias de inconstitucionalidad son constitutivas (como lo es cualquier norma derogatoria) y no declarativas $\mathrm{y}$, en consecuencia, las leyes no se declaran inexistentes sino que se constituyen inválidas, dada la actualización de un vicio de anulabilidad de las mismas (la infracción de la Carta Magna). En consecuencia, los efectos de las sentencias de los tribunales constitucionales bajo este modelo son pro futuro.

Así, como una norma jurídica cualquiera que no ha sido derogada todavía se conserva válida — produciendo todas sus consecuencias de derecho - hasta que la norma que la deroga disponga lo contrario, para quienes defienden esta tradición teórica, una norma que no ha sido declarada - o más bien constituida - inconstitucional se conserva válida hasta que la norma que la declara inconstitucional disponga lo contrario. Y así como es propio de una norma derogatoria producir sus efectos para el futuro, dejando intocado el pasado, una declaratoria de inconstitucionalidad sólo debe incidir en el futuro y no en el pasado.

Como es evidente, por tanto, defender la temporalidad ilimitada de una declaratoria de inconstitucionalidad o bien, un impacto exclusivamente pro futuro de éstas, es defender también un determinado entendimiento

3 Véase Kelsen, Hans, La garantía jurisdiccional de la Constitución, trad. de Rolando Tamayo y Salmorán, México, Instituto de Investigaciones Jurídicas, UNAM, 2001.

4 Cfr. García de Enterría, Eduardo, La Constitución como norma y el Tribunal Constitucional, 3a. ed., Madrid, Civitas, 1983. 
de los tribunales constitucionales: bien como verdaderas jurisdicciones o bien, como un legislador negativo.

No realizaríamos una exposición completa de estas dos posiciones, si no señaláramos las motivaciones políticas de inserción que tienen ambos. Un modelo que proponga privilegiar los efectos pro futuro de una declaratoria de inconstitucionalidad sobre la base del paradigma del legislador negativo, defiende el reconocimiento de una temporalidad para las normas generales exenta de la fiscalización de los jueces. El pasado constituye en éste un espacio para los poderes públicos en el que sus producciones jurídicas no pueden ser alcanzadas por los efectos de un juicio de constitucionalidad. Por el contrario, un modelo basado sobre el paradigma de la jurisdicción no reconoce estos espacios de exención a los órganos jurídicos. Los efectos de una declaratoria de inconstitucionalidad en el tiempo sólo se detienen ante las exigencias de los contenidos jurídicos que se reivindican con la resolución.

Bajo el modelo kelseniano del legislador negativo, se intenta minimizar los rasgos estructurales que otorgan al tribunal constitucional una superioridad en la organización estatal. Como sostiene García de Enterría, basar el diseño del tribunal constitucional en la idea de un legislador negativo tiene el propósito de contener el poder de los tribunales sobre los políticos, es decir, de evitar el "gobierno de los jueces". ${ }^{5}$ Para conservar la horizontalidad entre los órganos del Estado que esta construcción teórica persigue, es imprescindible que todos los órganos del Estado tengan la posibilidad de sustentar interpretaciones inatacables de la Constitución en algún grado - por más "incorrectas" que ellas sean- ${ }^{6} \mathrm{Si}$ el tribunal constitucional es un legislador negativo, emisor de normas derogatorias (constitutivas), como desde aquí se sostiene, la corrección que podrá realizar sobre su par, el legislador positivo, sólo es parcial. Así como todos los legisladores históricos están facultados sucesivamente para interpretar la misma realidad social con el único requisito de que sus interpretaciones, materializadas en normas coactivas, no corrijan retroactivamente las interpretaciones de los anteriores legisladores, sino sólo pro futuro, el tribunal constitucional comparte con el legislador positivo la facultad

5 Ibidem.

6 También se ha señalado que este modelo pretende evitar el gobierno de los jueces, evitando que el poder judicial ejerza por sí mismo (los jueces ordinarios) el control constitucional. 
originaria de interpretar la Constitución, con el único requisito que su interpretación correctiva no sea retroactiva sino prospectiva, como de hecho sucede con las interpretaciones correctivas que hacen los nuevos legisladores de las políticas jurídicas de sus antecesores. ${ }^{7}$

Sobre este punto, Salazar Ugarte considera que la articulación teórica kelseniana muestra una gran preocupación por evitar la objeción contramayoritaria y la forma cómo lo logra es simple: no trastocando la formulación clásica del principio de división de poderes. ${ }^{8}$ El Tribunal Constitucional es parte del poder legislativo, aunque su función no sea positiva como el democrático, sino negativa y dado que sus sentencias, como las leyes, son constitutivas y no declarativas, existe una complementariedad entre ambos más que una intromisión.

Por su parte, como anticipábamos, el paradigma de jurisdicción no impone estas barreras de horizontalidad a los jueces constitucionales. Siguiendo a Herbet Hart, la jurisdicción es una regla secundaria de adjudicación - las primarias son aquellas que prescriben contenidos materiales específicos- que se dirige a una categoría de funcionarios estatales para encargarles la función de determinar con autoridad cuándo se ha vulnerado el derecho. Hart considera que estos funcionarios se relacionan de una forma cualitativamente distinta con las normas jurídicas que el resto de los ciudadanos ordinarios: los jueces deben interiorizar las reglas jurídicas como criterios o pautas para valorar su conducta y la de los demás - lo llama el aspecto interno del derecho - con el mayor grado de intensidad posible. ${ }^{9}$

7 Kelsen sostuvo lo siguiente: "la eficacia retroactiva de las sentencias que declarasen la inconstitucionalidad de un precepto legal difícilmente podría ser justificada, no sólo por las consecuencias críticas de todo efecto retroactivo, sino especialmente porque la decisión concernía a un acto del legislador (constitucional), y el legislador también estaba autorizado para interpretar la Constitución, incluso cuando estuviese sometido en este aspecto al control judicial. Mientras el Tribunal no declare inconstitucional una ley, la opinión del legislador expresada en un acto legislativo tiene que ser respeatad", citado en Brage Camazano, Joaquín, La acción abstracta de inconstitucionalidad, México, UNAM, 2005, pp. 358 y 359.

8 Cfr. Salazar Ugarte, Pedro, La democracia constitucional. Una radiografía teórica, México, Fondo de Cultura Económica, Instituto de Investigaciones Jurídicas-UNAM, 2006.

9 Cfr. Hart Herbert, L. A., El concepto de derecho, trad. de Genaro R. Carrió, 2a. ed., Buenos Aires, Abeledo-Perrot, 2004. 
Con la introducción de la jurisdicción constitucional, como es evidente, las normas constitucionales también son cuidadas por una regla de adjudicación. La regla de adjudicación constitucional exige que los jueces interioricen las pautas constitucionales más que en cualquier otro nivel normativo. Para que la regla constitucional exista, es necesario que sea considerado desde el punto de vista interno como un criterio absoluto, común y público de decisiones judiciales correctas.

A la jurisdicción constitucional se le exige, desde esta perspectiva, una evaluación crítica-reflexiva de su realidad normativa, evaluación que debe culminar con una resolución que determine consistentemente y sin excepciones las consecuencias jurídicas de dichas pautas o criterios constitucionales. Por tanto, son los contenidos normativos de la Constitución, bajo el paradigma de jurisdicción, los que establecen los límites de los efectos de una declaratoria de inconstitucionalidad y no un respeto abstracto a las interpretaciones de los órganos del Estado fiscalizados ni una cierta horizontalidad en el diseño de éstos.

\section{EL PLANO EPISTEMOLÓGICO}

En el plano epistemológico, el objetivo es conocer la función jurídica de los tribunales constitucionales: ¿crean o descubren el derecho? La premisa es sencilla. Si los jueces crean derecho no deben aplicarlo de forma retroactiva - sobre todo cuando lo pretenden hacer con efectos generales- y, por tanto, las declaratorias de inconstitucionalidad deben tener un impacto exclusivamente pro futuro (una posición escéptica). Si, por el contrario, los jueces descubren el derecho, su aplicación puede ser, y en ocasiones debe ser, aplicado ex tunc, pues se trata de la reivindicación de pautas normativas predeterminadas y conocidas por todos (cognoscitivismo objetivo).

Dejando por un lado la discusión téorico-filosófica que ha ocupado a gran parte de la literatura de los dos últimos siglos, podemos afirmar que los jueces descubren el derecho igual que lo crean en algunas circunstancias. Ello no sólo porque todo acto de aplicación sea también un acto de creación, como nos aclara Kelsen, sino porque, en todo caso, el primer paso (el acto de aplicación), puede tener un carácter innovador notable.

Si tomamos como punto de partida un cognocitivismo jurídico moderado, como el que sugiere Hart, según el cual parte del derecho puede ser 
descubierto sin mayores problemas, mientras que otro sector del mismo se ubica en una zona de penumbra en el cual la opción interpretativa no está inequívocamente determinada, aunque tengamos que alejarnos de Hart y coincidir con Dworkin, en que la aplicación de este sector del derecho no es un ejercicio arbitrario, la respuesta que tenemos que dar a la pregunta de si un tribunal constitucional crea o descubre el derecho, dependerá del contexto en que nos ubiquemos. Aunque es cierto que la Constitución se integra de cláusulas abstractas, de elementos axiológicos contrapuestos y conceptos jurídicos esencialmente controvertidos en los que es necesario la deliberación y la interpretación más o menos libre, también existen núcleos de significación constitucional claros o evidentes que los tribunales constitucionales descubren para resolver los problemas que se les presentan, en los que no echan manos de sus propios recursos argumentativos e imaginativos.

Cuando un juez se encuentra ante un conflicto entre principios constitucionales, en la aplicación de alguna cláusula abstracta o de un concepto jurídicamente controvertido, es claro que necesita echar mano de actos de concreción que, en la mayoría de la casos, arrojan resultados especialmente controvertidos, dado que pueden existir otras razones que sugieran resoluciones opuestas. En todos estos casos, evidentemente, la función judicial es altamente creativa. Pero junto a éstos también hay casos en los que no es necesario escoger entre varias opciones interpretativas de igual valor jurídico, dado que suelen presentarse casos que se mueven el núcleo de algún principio o concepto constitucional, en los cuales una sola respuesta goza del consenso de la comunidad jurídica. Un tribunal constitucional conoce de ambos tipos de casos: difíciles y fáciles.

Por tanto, si se hace depender la cuestión de los efectos en el tiempo de una declaratoria de inconstitucionalidad de la pregunta sobre la verdadera tarea de los tribunales constitucionales, es claro que nuestro problema no puede resolverse de antemano, sino que depende de la evaluación del litigio concreto del que deriva (que sea un caso esencialmente controvertido o fácil, es decir, creativo, o no).

\section{EL PLANO AXIOLÓGICO}

En el plano axiológico, la solución de nuestro tema no se hace depender de la naturaleza del autor de las declaratorias de inconstitucionalidad 
ni de la operación jurídica que le dan origen, sino de los méritos de las pretensiones resueltas en cada uno de los casos concretos. De lo que se trata aquí es de evaluar el valor de los efectos retroactivos o prospectivos de una resolución en el contexto de los principios constitucionales involucrados.

No hace falta estudiar con gran cuidado el tema para percatarse que el principal argumento para proponer una incidencia exclusivamente pro futuro de una declaratoria de inconstitucionalidad se basa en el principio de seguridad jurídica. El mismo Kelsen, además de fundamentar su opinión en el carácter constitutivo de dichas sentencias, lo hizo en este principio: "[e]1 ideal de seguridad jurídica exige que, en general, no se atribuya efecto alguno a la anulación de una norma irregular más que profuturo, es decir, a partir de la anulación". ${ }^{10} \mathrm{~A}$ su vez, en nuestro país, el Constituyente Permanente hizo suya esta intuición para adicionar el penúltimo párrafo de la fracción III de la Constitución Federal en 1994: "por razones de seguridad jurídica y estabilidad social, aun cuando las declaraciones de inconstitucionalidad produzcan efectos, éstos habrán de limitarse en el tiempo a fin de impedir que las resoluciones tengan efectos retroactivos, con excepción de la materia penal".

¿Qué quiere decir, sin embargo, que una declaratoria de inconstitucionalidad no debe tener efectos retroactivos con el fin de salvaguardar el principio de seguridad jurídica?

Vayamos por partes. El principio de seguridad jurídica deriva del ideal generalizado de que el derecho debe ser capaz de proveer una guía efectiva para quienes están sujetos al mismo. ${ }^{11}$ Descansa en la idea de que para que las personas estén en aptitud de escoger las formas de vida que mejor les parezcan y puedan estar en condiciones de alcanzar los objetivos que se establezcan, es necesario que cuenten con puntos de referencia estables que otorguen certidumbre sobre su entorno. ${ }^{12}$ Sobre la base de estas razones, se considera que expulsar retroactivamente normas irregulares genera incertidumbre sobre el horizonte de consecuencias jurídicas en una comunidad determinada porque la individualización de dichas normas en innumerables casos ha producido situaciones consolidadas cuya

10 Kelsen, Hans, op. cit., nota 3, p. 44.

11 Raz, Joseph, "El Estado de derecho y su virtud", trad. de Rolando Tamayo, en Vázquez et al. (coords.), Estado de derecho, México, Siglo Veintiuno, p. 24.

12 Ibidem, pp. 26 y 27. 
supresión frustraría las expectativas formuladas sobre los actos que les dieron origen.

Aún más, la sistemática expulsión retroactiva de leyes por parte del tribunal constitucional socavaría la credibilidad de los poderes públicos fiscalizados, lo que redundaría directamente de forma negativa en la operatividad de la maquinaria estatal. Garantizar que las declaratorias de inconstitucionalidad sólo sean pro futuro es garantizar una indispensable certidumbre sobre el funcionamiento de las instituciones. Por tanto, en el centro del principio de seguridad jurídica no sólo está la previsibilidad de las consecuencias jurídicas de los individuos sobre sus actos propios, sino sobre todo una mínima eficacia asegurada al piso infraconstitucional que permite el funcionamiento de las instituciones públicas.

Sin embargo, el principio constitucional de seguridad jurídica, como es evidente, no se encuentra sólo en la jerarquía de valores que el derecho debe perseguir. La Constitución es un texto normativo que, como afirma Zagrebeslky, no deriva de un solo fundamento teórico, sino de varios y de diversos orígenes ideológicos. Al ser ello así, es evidente que en la carta magna convive una pluralidad de exigencias normativas planteadas por múltiples y con frecuencia contradictorios principios constitucionales que pretenden venir realizados en contacto con la realidad viva de las experiencias sociales. ${ }^{13}$

Si la Constitución es, pues, un conglomerado de principios que deben conciliarse por sus operadores para evitar "amputaciones de potencialidades constitucionales", ${ }^{14}$ es claro que la absoluta victoria del principio de seguridad jurídica en la determinación del exclusivo impacto pro futuro de las declaratorias de inconstitucionalidad no deja bien parados al resto de los principios con los que convive, especialmente con aquellos que son de un signo distinto y que intentan reivindicarse a través de las sentencias de los tribunales constitucionales.

El de seguridad jurídica es uno de aquellos que Atienza llama principios institucionales, los cuales asocia a las exigencias jurídicas estructurales necesarias para el sostenimiento de un ordenamiento jurídico. La tutela de este tipo de principios ayuda a preservar los aspectos vitales del propio derecho. Por su parte, existen los principios sustantivos, esto es,

13 Cfr. Zagrebelsky, Gustavo, El derecho dúctil. Ley, derechos, justicia, trad. de Marina Gascón, Madrid, Trotta, 1995.

14 Idem. 
no aquellos instrumentales a la propia estructura ósea del cuerpo jurídico, sino aquellos que conforman el programa político de convivencia social que se pretende realizar a través del derecho. ${ }^{15} \mathrm{Si}$ aceptamos esta división general de los principios, parece claro que la solución, según la cual las declaratorias de inconstitucionalidad deben ser únicamente prospectivas deja al descubierto su principal inconveniente. La tutela del principio de seguridad jurídica se realiza a costa de la plena reivindicación de los principios sustantivos que dicha declaratoria ha detectado como vulnerados. Esta tensión se actualiza en función de los casos resueltos. Si el tribunal constitucional detecta una violación al principio de igualdad, por ejemplo, la seguridad jurídica entra en conflicto con este principio y así sucesivamente, situación que podemos sintetizar diciendo que el principio de seguridad jurídica mantiene una relación de tensión con la "pretensión de corrección", contenida en la Constitución. ${ }^{16} \mathrm{Si}$ un tribunal constitucional sostiene que una ley es infractora de importantes principios constitucionales, su conclusión sólo podrá proyectarse en el plano práctico parcialmente: sólo se evita el daño futuro y se protege el realizado en el pasado. Para el futuro se reivindica el principio violado; para el pasado se tutela el de seguridad jurídica.

No obstante, la anterior descripción no debe llevarnos a afirmar, como nos advierte Atienza y Ruiz Manero, que ante todo conflicto entre ambas categorías axiológicas, los institucionales deben ceder ante los sustantivos, por la razón de que unos tienen valor intrínseco y los otros uno instrumental. Como nos puntualizan estos autores, muchas veces los institucionales tienen fuerza suficiente para derrotar a los de carácter sustantivo, dado que sin ellos, los sustantivos no podrían realizarse.${ }^{17}$ Por tanto, la solución opuesta tampoco es totalmente plausible. La total retroactividad de las declaratorias de inconstitucionalidad, en el lenguaje de Zagrebelsky, produce una amputación de una potencialidad constitucional que no puede aceptarse, que se refiere ni más ni menos a la operatividad del ordenamiento jurídico en su conjunto, necesaria para la realización de cualquier principio sustantivo democrático que tengamos en la mente.

15 Cfr. Atienza, Manuel et al., Las piezas del derecho, Barcelona, Ariel, 2004.

16 Esta expresión es tomada de Alexy, Robert, Teoría del discurso y derechos constitucionales, trad. de Pablo Larrañaga, México, Fontamara, 2005.

17 Atienza, Manuel et al., op. cit., nota 15. 
Por tanto, la solución de nuestro problema tampoco se puede obtener en este plano de antemano. Los principios tienen una dinámica operativa peculiar: dentro del ordenamiento constitucional tienen un valor prima facie y, por tanto, cada uno de ellos debe compaginarse con el resto de principios y exigencias constitucionales igualmente dignos de ser considerados. Robert Alexy sostiene que los principios constitucionales deben ser concebidos, en términos generales, como "mandatos de optimización" porque son normas que ordenan que algo se realice en la mayor medida posible en relación con las posibilidades jurídicas y fácticas. ${ }^{18}$ Esto hace necesario un ejercicio argumentativo, dado que los mismos sólo ofrecen razones prima facie, no concluyentes en el proceso de justificación jurídica. Este ejercicio de racionalización se conoce como ponderación. Zagrebelsky nos señala con puntualidad:

[1]a pluralidad de principios y la ausencia de una jerarquía formal entre ellos hace que no pueda existir una ciencia sobre su articulación, sino una prudencia en su ponderación... Quizás la única regla formal de la que quepa hablar sea la de la "optimización" posible de todos los principios, pero cómo alcanzar ese resultado es una cuestión eminentemente práctica y "material". ${ }^{19}$

\section{CONCLUSIÓN Y PROPUESTA}

Como puede concluirse con facilidad, estos tres planos pueden justificar individualmente distintas respuestas a la interrogante que nos hemos propuesto explorar en este artículo. Alguien podría defender, por ejemplo, que en nuestro país, la Suprema Corte de Justicia de la Nación debe emitir sus declaratorias de inconstitucionalidad con efectividad erga omnes solamente prospectivamente, justo en los términos en que actualmente lo establece el artículo 105 constitucional, alegando que la tradición que dota de sentido a su calificativo de tribunal constitucional se inscribe en la tradición europea de inspiración kelseniana, mientras que desde la otra posición, alguien podría oponer la fuerza de la tradición americana en nuestro sistema, defender el paradigma de jurisdicción y alegar lo injustificado de impedir que la Corte dote de retroactividad a sus reso-

18 Alexy, Robert, op. cit., nota 16.

19 Zagrebelsky, Gustavo, op. cit, nota 13, p. 125. 
luciones cuando el contexto constitucional así lo exija. Por otra parte, alguien podría demostrar que la Corte en los últimos tiempos ha resuelto una gran cantidad de casos altamente controvertidos en los que el texto constitucional no imponía una solución inequívocamente determinada y, por tanto, concluir que la notoria función creativa de la Corte fundamenta la conveniencia de la prospectividad de sus declaratorias y señalar lo perjudicial de su retroactividad. Finalmente, otros más podrían destacar la innegable carga axiológica de la Constitución mexicana, señalar el papel de árbitro de la Corte en los problemas entre principios constitucionales y sugerir que la presente cuestión se reduzca a una ecuación ponderativa, el cual determine caso por caso, los alcances temporales de las mencionadas declaratorias de inconstitucionalidad.

Desde mi perspectiva, los méritos propios de cada una de las tres líneas de argumentación, con las cuales nos hemos aproximado al fenómeno de los efectos temporales de los fallos erga omnes de la Suprema Corte, deben obligarnos a buscar un diseño que no excluya a ninguna de ellas y, por tanto, a adoptar la propuesta más plausible en su integración, que, en mi opinión, podría explorarse a partir de lo siguiente: que la incidencia temporal de sus decisiones debe ser una cuestión que la Suprema Corte, contra lo que prescribe actualmente el penúltimo párrafo del artículo 105 constitucional, pueda resolver con un amplio margen de discrecionalidad. Una reforma constitucional con este contenido se justifica en las siguientes tres razones:

1. La superación del paradigma del legislador negativo por el de jurisdicción. La concepción del tribunal constitucional kelseniano sirvió como una gran palanca histórica para apuntalar una garantía jurisdiccional de la Constitución en países con tradiciones políticas que ubican al parlamento como el centro indiscutible de las decisiones colectivas, dentro de los cuales era imperativo acomodar a un tribunal constitucional con las características necesarias para no amenazar un principio de división de poderes horizontal. Sin embargo, actualmente, este contexto político ha evolucionado a uno en el cual ya no es necesario este acomodo artificial: la teoría política ha logrado construir un concepto de democracia constitucional en la que la relación de los jueces constitucionales con los parlamentos se torna necesaria y ya no nociva o intrínsecamente contradictoria. 
Si ello es así, el concepto de "control" sobre el cual se puede basar nuestra concepción de un tribunal constitucional puede ser más flexible. En el paradigma del legislador negativo se parte de una idea de control horizontal en relación con el resto de los órganos estatales. Que las sentencias no fueran retroactivas implicaba asegurar que las interpretaciones constitucionales de los otros poderes se mantuvieran firmes para el pasado, lo cual se anclaba, como veíamos, en la premisa de que los tribunales constitucionales emitían actos de derogación más que de invalidez. La noción derogativa de la justicia constitucional, en tanto noción formal, no puede fundamentar una teoría del control satisfactoria porque el centro de gravitación de este último concepto lo conforma la idea regulativa de las "restricciones efectivas al poder" y la derogación es una categoría conceptual que pertenece a la teoría de las fuentes formales del derecho, que se presenta claramente insuficiente para este fin.

El proceso de sustitución del concepto de "derogación" por el de "invalidez" dentro de nuestro paradigma de tribunal constitucional, al cual también acude nuestro país, debe sentar raíces sobre una concepción de invalidez sustantiva, tal y como lo propone Luigi Ferrajoli. Este autor nos dice que en el Estado Constitucional las normas jurídicas deben tener dos propiedades: deben ser vigentes, pero también válidas. Esto es: no basta que las normas cumplan con las condiciones formales de su existencia (que sean emitidas conforme a los procedimientos establecidos para su creación y por las autoridades competentes), sino también deben cumplir con las condiciones de validez materiales (deben ajustarse con los contenidos materiales). Ello introduce la noción del "deber ser" (como categoría deontológica y no sólo epistémica) en el discurso jurídico, dado el resultado que arroja aplicar esta dicotomía a la realidad jurídica: en un ordenamiento determinado habrá normas vigentes que no sean válidas y, contra estas normas debe volcarse la función jurisdiccional en el ámbito constitucional, que, desde ahora, deja de ser un ente inanimado (la boca de la ley) para convertirse en un ente estatal extraordinariamente crítico de las producciones normativas de los poderes públicos, esto es, una jurisdicción sustantiva y activa. ${ }^{20}$ Sobre estas premisas, en mi opinión, debemos adoptar el paradigma de jurisdicción para explicar el fenómeno

20 Véase Gascón Abellán, Marina, "La teoría general del garantismo: rasgos principales", en Carbonell, Miguel et al., Garantismo. Estudios sobre el pensamiento jurídico de Luigi Ferrajoli, Trotta, UNAM, Instituto de Investigaciones Jurídicas, pp. 25-33. 
de los tribunales constitucionales, las cuales nos permite llevar hasta sus últimas consecuencias el principio de supremacía constitucional.

Es necesario aclarar que bajo esta nueva concepción, los efectos retroactivos no son un fin absoluto del control constitucional concentrado, sino uno más de los instrumentos al alcance de la misma, una posibilidad cuya realización depende de las necesidades fiscalizatorias de los casos concretos. De ahí, que desde esta perspectiva se aconseje la discrecionalidad de los Tribunales Constitucionales para determinar los alcances temporales de sus resoluciones.

2. En segundo lugar, como decíamos, en la actualidad no existe gran resistencia en reconocer que los jueces constitucionales no sólo aplican un derecho inequívoco e íntegramente preestablecido en los casos de los que conocen (desde donde se sugiere la retroactividad como reflejo de una función judicial declarativa), sino que también resuelven casos difíciles en los que despliegan una función integradora del derecho con un marcado componente creativo (desde donde se sugiere la prospectividad como un reflejo de una función judicial constitutiva). Si un tribunal constitucional conoce de ambos tipos de casos, cualquier propuesta que defienda uno de los extremos del debate con exclusividad (absoluta retroactividad o prospectividad), pareciera sugerir soslayar la compleja totalidad del fenómeno.

Por tanto, también desde este ángulo, la discrecionalidad en la determinación de los efectos temporales de los fallos es algo que se considera deseable. Esta discrecionalidad permite conseguir dos objetivos primordiales para el funcionamiento de cualquier Constitución democrática.

Por un lado, se logra que en los casos en que sea necesario, la Corte reivindique los contenidos nítidos de la Constitución, esto es, que otorgue retroactividad a contenidos normativos prestablecidos no controvertidos, dentro de los cuales el concepto de retroactividad se diluye frente al hecho de que las sentencias verdaderamente "aplican" el derecho con un notorio carácter "declarativo". Cuando un caso es resuelto de esta forma, podemos decir que los jueces cuidan una Constitución-garantía, la cual según Pérez Tremps, es aquella que busca imponerse a dinámicas políticas que frontalmente la desconocen (esto sucede principalmente en contextos políticos de transición en los cuales los jueces constitucionales juegan el importante papel de imponer la Constitución a la dinámica po- 
lítica caótica). ${ }^{21}$ En este contexto, es claro que la ausencia de los efectos retroactivos, convalida normas inconstitucionales, sin los cuales los poderes públicos no encuentran grandes incentivos para justificar sus actos en la Constitución.

Por el otro lado, la discrecionalidad permite que la Suprema Corte ayude a la Constitución a adaptarse al cambio social. Cuando surgen en la realidad litigios, en los cuales no existe por ninguna de las partes un notorio desconocimiento de la Constitución, sino que ponen sobre la mesa una conflictiva social que exige una lectura constitucional de nuevas circunstancias políticas - en otras palabras, proponen interpretaciones antagónicas de contenidos normativos controvertidos-, los jueces no cuidan una Constitución-garantía, como en la primera categoría de casos, sino una Constitución-directriz, la cual, según Pérez Tremps, busca conformarse como un instrumento de integración política y social, más que de reivindicación y dado que la función interpretativa que despliegan tiene un importante componente creativo, ${ }^{22}$ los efectos de las resoluciones de los tribunales constitucionales tienen una vocación prospectiva, justamente por la función que cumplen: reinterpretar la Constitución a la luz de las nuevas circunstancias sociales.

Dado que los conflictos puestos al conocimiento de la Suprema Corte pueden provenir de cualquiera de las dos categorías, la imposición de una sola posibilidad de efectos temporales de los efectos de sus sentencias (retroactivos o prospectivos) puede comprometer cualquiera de estos dos aspectos primordiales para una Constitución democrática (la reivindicación de sus contenidos normativos o su adaptación al cambio social).

3. Finalmente, una reforma constitucional que invista a la Suprema Corte con la facultad de modular con discrecionalidad la incidencia en el

21 Pérez Tremps, Pablo, Escritos sobre justicia constitucional, México, Porrúa, Instituto Mexicano de Derecho Procesal Constitucional, 2005, núm. 8.

22 Decimos "componen creativo" para simplificar un proceso más complejo que Manuel Atienza llama con puntualidad "enunciado interpretativo", esto es, un enunciado "emitido por un juez [en el que] no describe algo preexistente, pero tampoco puede verse simplemente como una prescripción, sino que se trata más bien de una creación peculiar, un desarrollo guiado -aunque no predeterminado en todos sus aspectos- por ciertos criterios (algo intermedio entre crear y aplicar) y que, en cierto modo, tiene algo de descriptivo y de prescriptito". Atienza, Manuel, El derecho como argumentación, Barcelona, Ariel, 2006, p. 56. 
tiempo de sus declaratorias de inconstitucionalidad, permite maximizar la fuerza normativa de todos los principios constitucionales.

Como se señaló, la actual prohibición constitucional a la Corte de dar efectos retroactivos a sus fallos tiene el propósito, desde un plano axiológico, de proteger la seguridad jurídica, salvo en la materia penal. Decíamos también que cuando se impide a la Corte invalidar una norma que viola un principio constitucional distinto al de seguridad jurídica, se impide que el contenido violado se reivindique totalmente, lo cual simplificábamos diciendo que el principio de seguridad jurídica tiene una relación de tensión con la pretensión de corrección que subyace constitucionalmente. Finalmente, decíamos que es una afirmación presupuesta que siempre que haya principios constitucionales involucrados, el operador jurídico está obligado a ponderar.

La ponderación realizada por el Constituyente Permanente en el penúltimo párrafo del artículo 105 constitucional varía dependiendo si nos ubicamos en la materia penal o si nos ubicamos en el resto de la topografía constitucional. En la materia penal se resalta el papel secundario del principio de seguridad jurídica, mientras que en los demás su superioridad absoluta. Aquí nos hemos referido a la pretensión de corrección como un principio contrapuesto al de seguridad jurídica, pero en realidad esta noción intenta simplificar, como habíamos dicho, al conjunto (heterogéneo) de principios sustantivos e institucionales contemplados en la Constitución. Por tanto, cuado se permite que los fallos de la Suprema Corte tengan efectos retroactivos en la materia penal, ello refleja una ponderación concreta entre un principio sustantivo y otro institucional: entre el principio de libertad personal y el de seguridad jurídica. Para el poder reformador de la Constitución, cuando el principio de la libertad personal se encuentre en conflicto con el principio de seguridad jurídica, este último debe ceder siempre frente al primero - la eficacia del aparato estatal no puede asegurarse a costa de este derecho fundamental- Sin embargo, la ponderación es distinta cuando nos salimos de esta materia. En todos los demás casos en que el principio de seguridad jurídica entre en conflicto con el resto de principios constitucionales (sustantivos o institucionales), el de seguridad jurídica prevalece (inclusive, sobre el resto de los derechos fundamentales).

Esta interpretación del penúltimo párrafo del artículo 105 constitucional nos permite inferir un hecho bastante plausible: el Constituyente 
Permanente al momento de redactar el penúltimo párrafo del artículo 105 constitucional se preocupó por ponderar cuidadosamente el principio de seguridad jurídica con el principio de la libertad personal, pero claudicó de continuar esta tarea con el mismo cuidado en el resto de los conflictos axiológicos posibles. En el resto de materias jurídicas se limitó a establecer una regla que impone un idéntico resultado a un conjunto heterogéneo de conflictos axiológicos.

Sin embargo, debemos reconocer que el Constituyente Permanente no es el sujeto más idóneo para ponderar de una vez y para siempre todos los principios constitucionales para establecer una matriz que determine con detalle en qué casos la Suprema Corte de Justicia de la Nación puede dotar de efectos retroactivos a sus fallos en el contexto de las controversias constitucionales y las acciones de inconstitucionalidad y en cuáles no, porque ello simplemente es una tarea imposible. En los términos en que lo expresa Robert Alexy, "[e]s imposible una teoría fuerte de los principios de forma que determine para cada caso precisamente una respuesta". ${ }^{23} \mathrm{Si}$ el Constituyente Permanente se volcara en una empresa de este tipo sólo produciría criterios cerrados que harían absolutas relaciones que por definición sólo aceptan proposiciones relativas.

Hechas estas consideraciones, podemos observar, finalmente, con nitidez una de las principales desventajas de la actual prohibición de la $\mathrm{Su}$ prema Corte en otorgar efectos retroactivos a sus decisiones y una de las principales ventajas de la propuesta de que sea ella la que determine esta cuestión con amplia libertad: la actual prohibición impide que todos los principios constitucionales, excepto el de la libertad personal, sean mandatos de optimización frente al principio de seguridad jurídica. Bajo la actual regla, los principios constitucionales no pueden ponderarse según las exigencias de los casos concretos, y por ello, es imposible que éstos adquieran su máxima eficacia jurídica, según las posibilidades jurídicas y fácticas. Esto, sin embargo, desaparecería si se permitiera que la Corte tuviera discrecionalidad para determinar los efectos de sus decisiones, pues bajo esa facultad, podría ponderar en cada caso concreto los principios que entraran en conflicto, con lo cual se lograría que todos ellos sean efectivamente mandatos de optimización.

Bajo un modelo como el propuesto, se podría lograr lo siguiente. Siguiendo los ejemplos dados al inicio, si la norma declarada inconstitucio-

23 Alexy, Robert, op. cit., nota 16, p. 20. 
nal es aquella que excluye a un sector de la población injustificadamente del acceso a un bien público amparado constitucionalmente, la sentencia de la Corte podría retrotraerse, dejar insubsistente las negativas emitidas por las autoridades contra las personas afectadas y, por tanto, las personas podrían reclamar la reivindicación de los bienes denegados. En otro ejemplo, si la norma declarada inconstitucional, es una que establece una división competencial entre la Federación y un Estado, referente a la prestación de un servicio público, la sentencia podría emitirse sólo para regir para el futuro y dejar intactas las consecuencias jurídicas pasadas a las cuales se adaptó la población durante ese tiempo. Sin embargo, si se trata de una norma que establecía un tipo de responsabilidad distinta a la penal, sobre la base de una conducta protegida constitucionalmente, se le puede dotar de efectos retroactivos a la resolución y dejar insubsistentes todas aquellas determinaciones definitivas realizadas contra las personas afectadas. Pero si se trata de una sentencia que declara inconstitucional una ley que prohíbe a los jueces ordinarios analizar la regularidad constitucional de normas, sobre la base de una nueva interpretación del artículo 133 constitucional, por poner un ejemplo que podría ser más real, con la cual se aparta de una tradición jurisprudencial consolidada, es claro que la misma debería tener efectos exclusivamente prospectivos y dejar intactas todas aquellas situaciones jurídicas construidas al amparo de la anterior doctrina constitucional. No obstante, si se trata de una norma que dota de competencia al poder ejecutivo para juzgar civilmente a las personas, la sentencia debería retrotraerse. 